International Braz J Urol

Vol. 34 (3): 355-364, May - June, 2008

\title{
Zoledronic Acid Effects Interleukin-6 Expression in Hormone- Independent Prostate Cancer Cell Lines
}

\author{
Layka A. Asbagh, Selim Uzunoglu, Cag Cal
}

Department of Molecular Biology (LAA, SU), Faculty of Science and Arts, Celal Bayar University, Manisa, Turkey, and Department of Urology (CC), School of Medicine, Ege University, Izmir, Turkey

\begin{abstract}
Objective: To investigate the inhibitory effects of zoledronic acid (ZA) on tumor related growth factor IL-6 in hormone resistant prostate cancer cell lines. The association between apoptosis and IL-6 inhibition was also assessed.

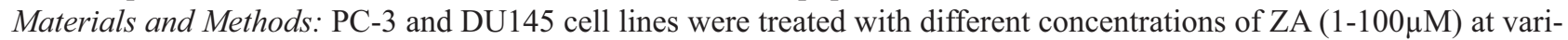
ous intervals (24-72 h.). The cell viability was investigated by XTT assay and apoptotic effect was evaluated by cell death detection ELISA kit. Caspase 3/7 activity assay was performed to confirm apoptosis. IL-6 levels were measured by ELISA in the supernatant, and these data were also confirmed by IL-6 mRNA analysis using RT-PCR.

Results: PC-3 and DU145 cell lines were sensitive to ZA mediated cytotoxicity in a dose- and time-dependent manner. However, the apoptotic effect was significantly different among PC-3 and DU145 cells ( $p<0.05)$. IL-6 secretion was significantly lower in both cell lines, compared to the untreated control cells $(\mathrm{p}<0.05)$. Although the increased inhibition of IL-6 secretion was associated with increased apoptosis in DU145 cells $(p=0.002)$, there was no similar association for PC-3 cell line $(p=0.347)$. When compared to the untreated controls, the number of cDNA copies was significantly lower in the ZA treated DU145 cell line at doses of 30 and $90 \mu \mathrm{M}(\mathrm{p}<0.05)$, suggesting a reduced expression of IL- 6 mRNA. Conclusion: ZA exhibited a time- and dose-dependent apoptotic effect on PC-3 and DU145 prostate cancer cell lines and this effect was associated with inhibited secretion of IL-6 in DU145 cell line.
\end{abstract}

Key words: prostate cancer; zoledronic acid; interleukin-6; experimental

Int Braz J Urol. 2008; 34: 355-64

\section{INTRODUCTION}

Prostate cancer is most common among elderly men, and in 2007, the estimated number of the newly diagnosed prostate cancer cases was 218.890 in USA (1). Although local curative treatment strategies are the most appropriate procedures in organ-confined disease, androgen deprivation therapy represents the standard treatment in patients with metastatic prostate cancer. Nevertheless, the development of hormone resistant prostate cancer and progression is inevitable during androgen deprivation treatment. Unfortunately, no any other effective and curative alternative treatment has been reported for these patients.

The new treatment modalities are primarily focused on growth factors that stimulate the proliferation of prostate cancer cells. Interleukin-6 (IL-6) is a growth factor for prostate cancer cells and its high serum levels are known to be directly associated with clinical prognosis of the disease $(2,3)$. It has also been shown that IL-6 signaling pathway is active and upregulated in organ-confined prostate tumors (4) and 
IL-6 signaling pathway is actively used in metastatic prostate cancers and hormone independent prostate cancer cell lines.

Several clinical trials have already demonstrated the beneficial effects of bisphosphonates in prostate cancer patients $(5,6)$. The growth of metastases may be inhibited by modifying the bone microenvironment using bisphosphonates. They also exert direct cytotoxic and apoptotic effects on a variety of human tumor cell lines including myeloma, breast cancer and prostate cancer (7-9).

Zoledronic acid (ZA) is the most potent nitrogen containing bisphosphonate compound. It has been shown to inhibit cell growth and induce apoptosis in prostate cancer cell lines DU145, PC-3 and LNCaP (10). Current evidence on the effects of ZA suggests that it is a potential chemotherapeutic agent for the treatment of prostate cancer, either as monotherapy or in combination. Despite the overwhelming in vitro studies investigating the anti-tumor activity of the combined use of ZA with different chemotherapeutics, the molecular targets and mechanisms of ZA in tumor cells remains a subject of debate.

We hypothesize that ZA may exert its antitumor effect by inhibiting the tumor related growth factor IL-6. Considering the potential role of IL-6 in the growth regulation of PC-3 and DU145 cell lines, the present study was planned to investigate the relationship between the anti-tumor activity of ZA and IL-6 secretion in these cells under in vitro conditions.

\section{MATERIALS AND METHODS}

Chemicals - Cell culture supplies were obtained from Biological Industries (Kibbutz Beit Haemek, Israel). Zoledronic acid was a generous gift from Novartis Pharmaceuticals Inc. (Basel, Switzerland). The stock solution of zoledronic acid was prepared at a concentration of $1 \mathrm{mM}$ in distilled water and aliquots were stored at $-20^{\circ} \mathrm{C}$. All other chemicals, unless otherwise mentioned, were purchased from Sigma Chemical Co (USA).

Cell lines and culture - The androgen-refractory prostate cancer cell lines, PC-3 and DU145, were preferentially used since they secrete IL- 6 and actively use IL-6 signaling pathway for growth promoting effects (11) and to maintain resistance to chemotherapy. These cell lines were kindly provided by Dr. Levent Turkeri from Marmara University, Istanbul, Turkey. PC-3 and DU145, adherent cell lines were cultured in RPMI 1640, supplemented with $10 \%$ heat-inactivated fetal bovine serum, $1 \%$ L-glutamine and $1 \%$ penicillin-streptomycin. All cell cultures were incubated at $37^{\circ} \mathrm{C}$ in $5 \% \mathrm{CO}_{2}$ and $95 \%$ air.

Cell viability assay - The effects of different concentrations of zoledronic acid $(1,10,30,60,90$, and $100 \mu \mathrm{M})$ on PC-3 and DU145 cell lines were evaluated by using XTT cell proliferation kit (Roche Applied Science, Mannheim, Germany). Following the verification of cell viability by tryptan blue exclusion test, cells were plated on a 96 -well plate in $200 \mu \mathrm{L}$ culture medium at a concentration of $10^{4}$ cells/well. At 24,48 and 72 hours of incubation, a $50 \mu \mathrm{L}$ of XTT labeling mixture was added to each well. The optical density was measured at $450 \mathrm{~nm}$ with a reference wavelength at $650 \mathrm{~nm}$ using a microplate reader (Beckman Coulter, DTX 880 Multimode Reader). The percentage of cytotoxicity was calculated as follows:

$\%$ Cystotoxicity $=1-\frac{\text { A of experimental well }}{\text { A of positive control well }} \times 100$

where $\mathrm{A}$ is the absorbance.

Evaluation of apoptosis - The Cell Death Detection ELISA kit (Roche Applied Science, Mannheim, Germany) was used to detect mono-oligonucleosomes (histone-associated DNA fragments) as an indicator of apoptosis after zoledronic acid induced cell death. Briefly, cytoplasmic lysates from untreated controls and zoledronic acid treated cells were transferred to a streptavidin-coated plate supplied by the manufacturer. A mixture of Anti-histone-biotine and AntiDNA-POD were added to cell lysates and incubated for 2 hours. The complex was then simultaneously conjugated to form an immune complex on the plate, which then was read for optical density at $405 \mathrm{~nm}$ with a reference wavelength at $490 \mathrm{~nm}$. The enrichment of mono-oligonucleosomes in cell lysates was calculated as absorbance of zoledronic acid treated cells/absorbance of untreated controls. 
Caspase 3/7 activity assay - The CaspaseGlo 3/7 assay (Promega, Madison, WI) was used to measure caspase $3 / 7$ activity, according to the manufacturer's instructions. PC-3 cells were plated on a 96 -well plate in $100 \mu \mathrm{L}$ culture medium at a concentration of $10^{4}$ cells/well. After incubation with increasing concentrations of zoledronic acid, $100 \mu \mathrm{L}$ of Caspase-Glo 3/7 reagent was added to each well. Then the mixture was incubated for one hour at room temperature and the luminescence of each sample was measured using a plate-reading luminometer (Beckman Coulter, DTX 880 Multimode Reader).

Determination of interleukin-6 secretion - IL-6 levels were quantified in the supernatants of zoledronic acid treated PC-3 and DU145 cells by using Human IL-6 ELISA Kit (Biosource International Inc., California, USA). The cells were plated on 24well plates at a concentration of $10^{5}$ cells per well and incubated for 24, 48 and 72 hours with increasing concentrations of zoledronic acid $(1-100 \mu \mathrm{M})$. Supernatants were collected for all culture conditions and analyzed for IL-6 levels using a standard ELISA kit according to manufacturer's instructions. Standard curve for quantification was plotted from values of IL-6 standards provided by kit. IL-6 levels in zoledronic acid treated cells were recalculated based on the IL-6 levels from untreated control cells at the end of treatment in order to compensate the differences due to cell number. The decrease in IL-6 levels was also confirmed by RT-PCR.

Expression of IL-6 mRNA - The effect of zoledronic acid on IL-6 mRNA level was investigated by RT-PCR. RNA samples from untreated controls and DU-145 treated cells were isolated by using High Pure RNA Isolation Kit (Roche Applied Science, Mannheim, Germany). Primers and probes were included in Roche LightCycler Primer set (Human Interleukin-6). The procedure was carried out as a single step method for reverse transcription from RNA to cDNA and subsequent quantification was made without opening the reaction tube. A Roche Light Cycler apparatus was used with the following sequence: denaturation at $95^{\circ} \mathrm{C}$ for 10 minutes, then 35 cycles of amplifications for $10 \mathrm{~s}$ at $95^{\circ} \mathrm{C}, 10 \mathrm{~s}$ at $68^{\circ} \mathrm{C}, 16 \mathrm{~s}$ at $72^{\circ} \mathrm{C}$, and a final cooling step to $40^{\circ} \mathrm{C}$. The data were analyzed by the software of Roche LightCycler (1.5) Instrument.
Statistical analyses - All experiments were set up in triplicate and the results were expressed as mean \pm standard deviation (SD). GraphPad PRISM software (version 5) (San Diego, CA, USA) was used for the analysis of data and graphic presentations. Student's t-test or ANOVA was used for comparisons.

\section{RESULTS}

The cytotoxic and apoptotic effects of zoledronic acid - PC-3 and DU145 cell lines were sensitive to ZA mediated cytotoxicity; the maximum cytotoxicity was achieved at 72 hour with $100 \mu \mathrm{M}$ concentration of ZA. The cytotoxicity was proportional with the increasing concentrations of ZA for both cell lines and the difference from untreated controls was statistically significant $(p<0.05)$. (Data not shown). ZA induced time- and dose-dependent apoptosis in both cell lines. Data for PC-3 cell line regarding apoptosis is given in Figure-1. For PC-3 cell line, Caspase 3/7 activity was significantly increased in ZA treated cells, compared to untreated controls $(\mathrm{p}<0.05)$ (Figure-2).

IL-6 secretion as detected in the supernatants of PC-3 and DU145 cells - Incubation of PC-3 and DU145 cells with increasing concentrations of ZA for 24,48 and 72 hours resulted in a significant dosedependent decrease in IL-6 secretion $(\mathrm{p}<0.05)$ (Figure-3 and 4). This effect was detected with the lowest dose and at the earliest time points. A difference in terms of dose-dependent inhibition of IL- 6 secretion between two cell lines could only be observed at 72 hours. The lowest level of IL-6 secretion was achieved at 24 hours for PC-3 cells.

For DU-145 cells, a four-fold decrease in IL-6 secretion was found in ZA treated cells with 60 $\mu \mathrm{M}$ and higher concentrations, compared to untreated controls. However, for PC-3 cells, IL-6 secretion was only halved with the same concentrations and IL-6 secretion was significantly higher in DU145 cells than PC-3 cells $(\mathrm{p}<0.05)$.

Interestingly, for PC-3 cell line, there was no association between the degree of apoptosis and inhibition of IL- 6 secretion following ZA treatment, $(p=0.347)$. In contrast, for DU145 cells, the inhibition of IL-6 secretion was correlated with the degree of apoptosis $(\mathrm{p}=0.002)$. 


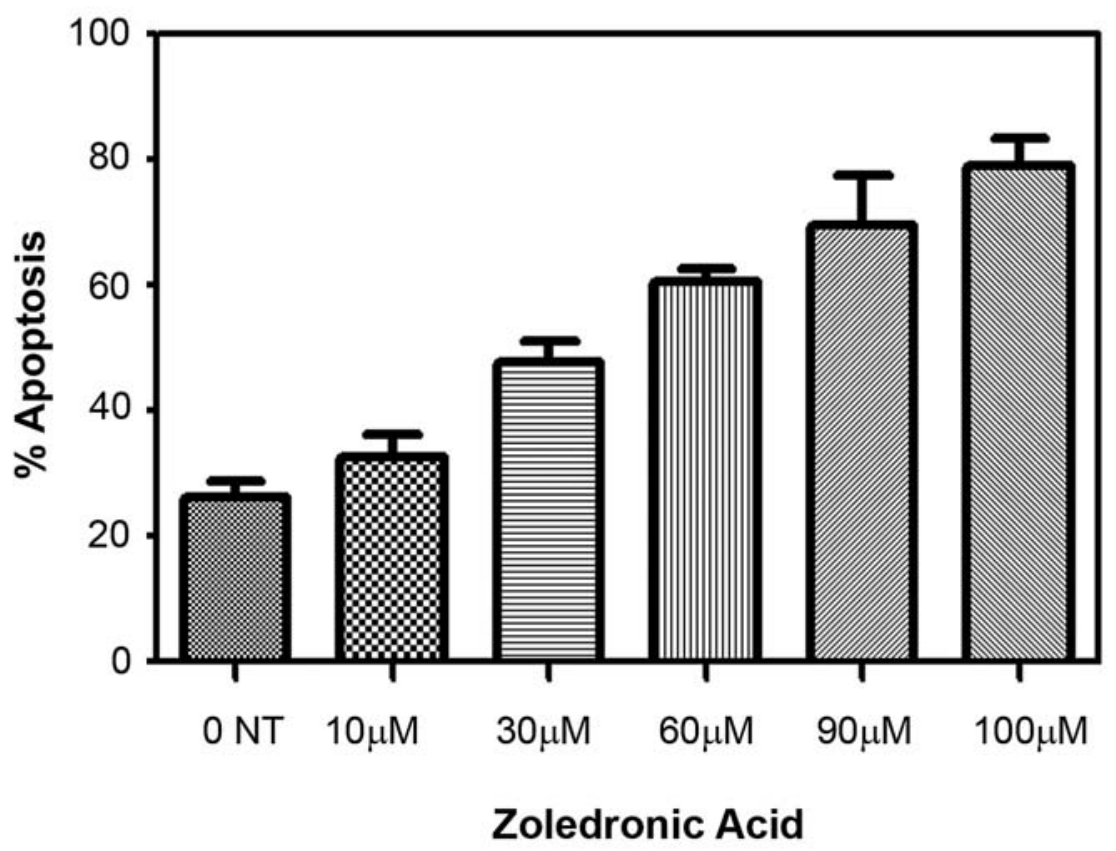

Figure 1 - Concentration dependent relative apoptosis in PC-3 cell line following exposure to zoledronic acid. PC-3 cell line was treated with increasing concentrations of zoledronic acid for 72 hours and then the levels of mono-oligo nucleosome fragments was quantified using Cell Death Detection Kit. Columns, the means of two independent experiments; bars, SD. 0 NT, untreated controls. $P<0.05$, vs. controls.

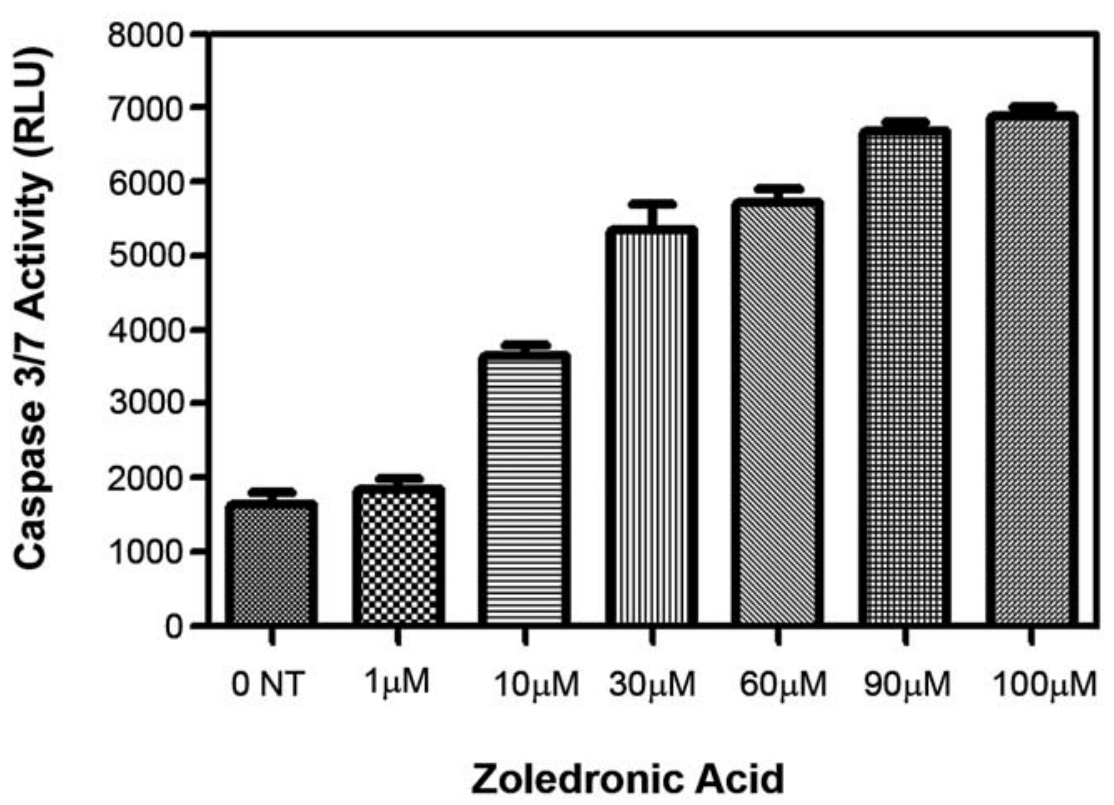

Figure 2 - Concentration dependent caspase 3/7 activity in PC-3 cell line following exposure to zoledronic acid. PC-3 cell line was treated with increasing concentrations of zoledronic acid for 72 hours and then the levels of caspase 3/7 was measured using caspaseGlo 3/7 assay. Columns, the means of two independent experiments; bars, SD. 0 NT, untreated controls. $P<0.05$, vs. controls. 


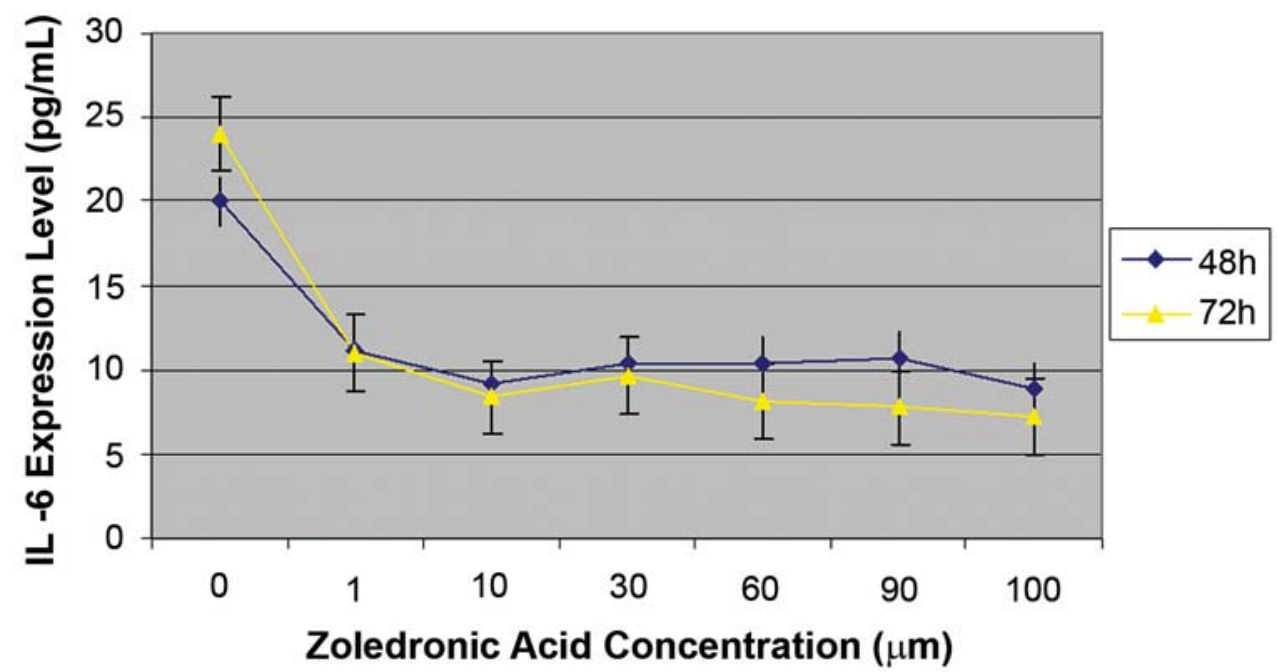

Figure 3 - Effect of zoledronic acid treatment on IL-6 secretion in PC-3 cell line. $10^{5}$ viable cell/well was treated with increasing concentrations of zoledronic acid. IL-6 levels were measured after 48 and 72 hours by ELISA in the supernatants of zoledronic acid treated cells. Points, the mean of at least three independent experiments; bars, SD. 0, untreated controls. $P<0.05$, vs. controls.

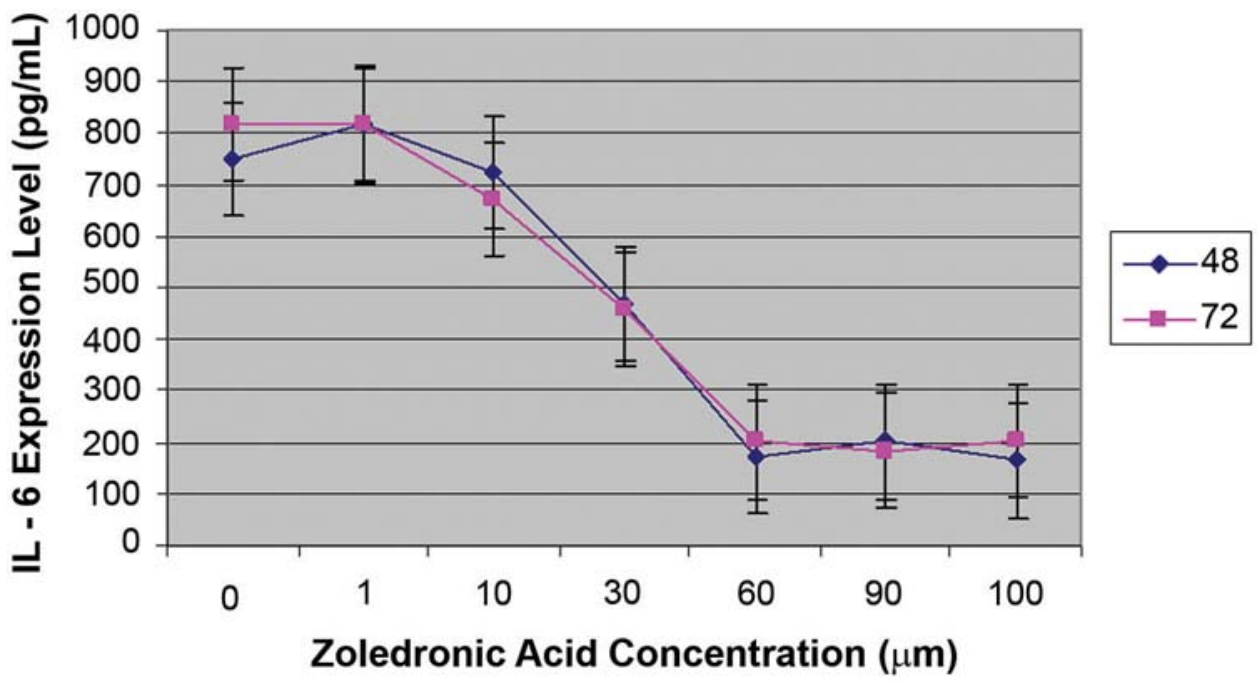

Figure 4 - Effect of zoledronic acid treatment on IL-6 secretion in DU145 cell line. $10^{5}$ viable cell/well was treated with increasing concentrations of zoledronic acid. IL-6 levels were measured after 48 and 72 hours by ELISA in the supernatants of zoledronic acid treated cells. Points, the mean of at least three independent experiments; bars, SD. 0, untreated controls. P $<0.05$, vs. controls.

Measurement of IL-6 mRNA levels in ZA treated DU145 cells by RT-PCR - RT-PCR was performed in DU-145 cells, in order to examine whether the reduction of IL-6 levels is associated with a de- creased expression of IL-6 mRNA. The number of cDNA copies was significantly lower in DU-145 cells treated with 30 and $90 \mu \mathrm{M} \mathrm{ZA}$, compared to untreated controls $(\mathrm{p}<0.05)$ (Figure-5). 
A

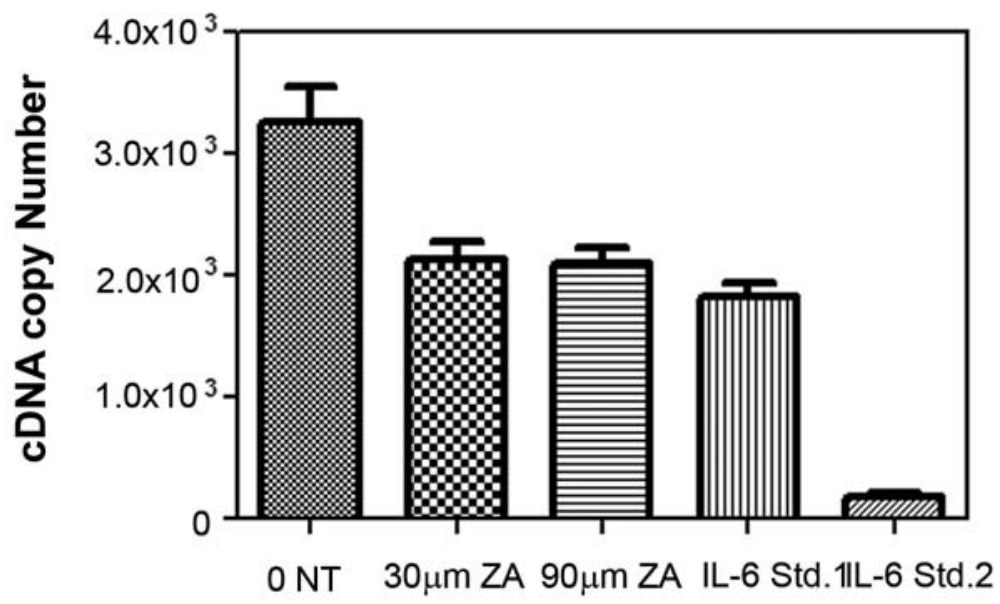

B

\begin{tabular}{|l|l|l|}
\hline Sample Name & $\begin{array}{l}\text { Calculated } \\
\text { Concentration }\end{array}$ & $\begin{array}{l}\text { Crossing } \\
\text { Point }\end{array}$ \\
\hline $0 \mathrm{NT}$ & $3.454 \mathrm{E}+02$ & 27.37 \\
\hline $30 \mu \mathrm{M}$ ZA & $2.014 \mathrm{E}+02$ & 28.17 \\
\hline $90 \mu \mathrm{M}$ ZA & $2.187 \mathrm{E}+02$ & 28.04 \\
\hline IL-6 Std.1(1.900E + 03) & $1.900 \mathrm{E}+03$ & 24.85 \\
\hline IL-6 Std.2(1.900E + 02) & $1.881 \mathrm{E}+02$ & 28.27 \\
\hline
\end{tabular}

Figure 5-IL-6 mRNA expression levels of DU-145 cell line after zoledronic acid treatment. A) DU145 cell line was treated with $30 \mu M$ and $90 \mu M$ concentrations of zoledronic acid for 72 hours and then IL-6 mRNA expression levels (as cDNA copy number) were measured by RT-PCR (Roche LightCycler 1.5 System). 0 NT, untreated controls. IL-6 std. 1 and 2 correspond to $1.900 E+03$ and $1.900 E+02$ copies of IL-6 mRNA, respectively. Columns, the mean of at least two independent experiments; bars, SD. P<0.05, vs. controls. B) IL-6 standards were used for reference. Amplification of two standards allow the analysis of sample concentration.

\section{COMMENTS}

The present study confirmed that ZA induces apoptosis in PC-3 and DU145 prostate cancer cell lines in a dose- and time-dependent manner. However, the extent of this effect was significantly different for PC-3 and DU145 cell lines. In addition, two cell lines differed in terms of IL-6 secretion. The degree of apoptosis was not related to the level of the inhibition of IL-6 secretion for PC-3 cells, which also secrete low levels of IL- 6 compared to DU145 cells. On the other hand, the level of reduction in IL-6 secretion was correlated with the degree of ZA induced apoptosis in DU145 cell lines. Based on this data, it might be speculated that anti-tumoral effects of ZA could also be mediated by IL- 6 and related signaling pathways in prostate cancer cells.

It has been well-documented that IL- 6 is a multifunctional cytokine that plays an important role in the regulation of hematopoiesis, immune response, inflammation, bone metabolism and neural development (12). It is produced by different cells including lymphoid or non-lymphoid cells and malignant tissues (13). All prostate cells including normal prostate epithelia, cells originated from benign prostatic hyperplasia and malignant prostate cancer are shown to be capable of secreting IL-6 in cell cultures (14). Furthermore, increased secretion of IL-6 ligand and its receptors in serum has been reported for all stages of prostate cancer including hormone refractory pa- 
tients $(14,15)$. Also, clinical prognosis of prostate cancer is directly affected by serum IL-6 levels (15) and IL- 6 plays an important role for the development of resistance to chemotherapeutics used in prostate cancer (16). Moreover, exogenous administration of IL-6 has been shown to inhibit doxorubicin-induced apoptosis in PC-3 cells (17).

In vitro studies demonstrated an increase in the proliferation of prostate cancer cells with IL-6 stimulation $(18,19)$ and a decrease in growth rate of androgen insensitive PC-3 and DU145 cell lines treated with anti-IL-6 antibodies (16). These results suggest that the combined use of anticancer agents with drugs resulting in an inhibition of IL-6 expression could increase the efficacy of chemotherapy, particularly in patients with hormone refractory prostate cancer.

However, conflicting results have been reported regarding the stimulatory/inhibitory effects of IL-6 on the proliferation on various prostate cancer cell lines $(11,20,21)$. These differences may be attributed to a several reasons related to IL-6 signaling pathway. Firstly, there are membranous and soluble forms of IL6 ligand and its receptor, which are strictly regulated. Secondly, gp130, the signal transducer of IL-6 on the membrane, can be activated by various growth factors. Thirdly, activated gp130, either simultaneously or preferentially, triggers three intracellular pathways by the alteration of intracellular domain. IL-6 signaling is mediated by JAK-STAT, ras-raf-MAPK and PI3K-Akt signaling. It has been suggested that one or two alternative pathways are preferentially more active in different cell lines. IL-6 can also be up- and down regulated by autocrine or paracrine effects and feed-back mechanism $(11,20,22,23)$. Its expression is regulated by several transcription factors such as $\mathrm{AP}-1, \mathrm{NF} \kappa \mathrm{B}, \mathrm{CREB}$ and $\mathrm{c} / \mathrm{EBP}$. It is considered that intracellular signaling pathways of IL-6 also regulate these transcription factors.

Zoledronic acid may affect a some molecules in signal transduction pathways including cell proliferation process (ras-raf-MAPK), tumor suppressor genes, apoptotic pathways, cell cycle proteins and posttranslational processes. Since ZA affects the binding of ras proteins to the membrane via protein prenylation (10), it might indirectly inhibit cell proliferation. In a recent study by Cavarretta et al., the effect of IL-6 was shown to be mediated by oncogene Mcl-1 (myeloid cell leukemia-1), an anti-apoptotic member of the Bcl-2 family in prostate cell line (24). The association between ZA treatment and IL-6 secretion may also be regulated by Mcl-1 expression.

Several authors have previously suggested that ZA cannot induce apoptosis $(9,25)$. Such an inconsistency might be explained by the differences in ZA concentrations (25) and treatment durations (9). The present study indicates that a longer treatment period with higher concentrations of ZA is necessary to induce apoptosis. Interestingly, when bisphosphonates are combined with other common anti-neoplastic drugs, a significant synergy occurs. The synergic cytotoxic effect of ZA has previously been detected on prostate cancer cells $(26,27)$.

Few studies investigated the relation between IL-6 expression/secretion and ZA treatment. A decreased IL- 6 expression has been reported after ZA treatment in bone marrow stromal cells under in vitro conditions $(28,29)$. On the contrary, a transient induction of an increase in TNF-alpha and IL-6 levels with $\mathrm{ZA}$ infusion has been demonstrated in cancer patients with fever (30). Although the disagreements between the studies may be explained by the variations of in vivo and in vitro conditions, all of these observations clearly points out that IL-6 has an important role in the processes related to both bone microenvironment and metastases in prostate cancer (31). The present study shows a correlation between the degree of ZA induced apoptosis and the inhibition of IL-6 secretion, implying that the apoptotic effect of ZA is associated with IL- 6 and related pathways. Exogenous administration of IL- 6 do not interfere the anticancer actions of ZA on PC-3 cells, which supports the above-mentioned association (17).

These findings raise two possible interpretations: either the reduction of IL-6 secretion itself induces the apoptotic process or it may be the outcome of ZA induced apoptosis in a dose dependent manner. If no significant correlation had been found between the decrease in IL- 6 expression and the degree of apoptotic process, it could be suggested that ZA directly inhibits the autocrine mechanisms of IL-6 expression.

It would also be worth mentioning that ZA may indirectly induce apoptotic mechanisms through 
affecting signal transduction pathways on the upstream region of apoptotic pathway. This probability may explain the reduction of IL-6 secretion with increased apoptosis, which was observed after ZA treatment in our study. Therefore, it can be suggested that ZA not only directly induces apoptotic pathways, but also indirectly affects one or more signal transduction molecules located on upstream region, which cause the apoptosis in PC-3 and DU145 cell lines. For these reasons, it is necessary to determine the target molecules that play key roles on the effects of ZA.

\section{CONCLUSION}

The present in vitro study shows a time- and dose-dependent apoptotic effect of ZA on both PC-3 and DU145 prostate cancer cell lines, which correlates with an inhibitory effect on IL-6 expression in DU145 cells. Additional research is required to further elucidate the activity of IL- 6 and its role in the pathogenesis of advanced prostate cancer at cellular and molecular levels. Also, further studies are required to investigate the down regulation of oncogene Mcl-1 (myeloid cell leukemia-1), an anti-apoptotic member of the Bcl-2 family, which is regulated directly by IL-6 in ZA treated cells (24). The inhibition of IL-6 with anti-IL6 antibody sensitizes androgen-independent prostate cancer cells to chemotherapeutic agents in vitro (32); thus, treatment modalities targeting IL-6 may have multiple advantages in prostate cancer patients who receive limited therapeutic and survival benefit from conventional treatment alternatives (18).

\section{CONFLICT OF INTEREST}

$$
\text { None declared. }
$$

\section{REFERENCES}

1. Jemal A, Siegel R, Ward E, Murray T, Xu J, Thun MJ: Cancer statistics, 2007. CA Cancer J Clin. 2007; 57: 43-66.

2. Culig Z, Steiner H, Bartsch G, Hobisch A: Interleukin-6 regulation of prostate cancer cell growth. J Cell Biochem. 2005; 95: 497-505.
3. Nakashima J, Tachibana M, Horiguchi Y, Oya M, Ohigashi T, Asakura H, et al.: Serum interleukin 6 as a prognostic factor in patients with prostate cancer. Clin Cancer Res. 2000; 6: 2702-6.

4. Giri D, Ozen M, Ittmann M: Interleukin-6 is an autocrine growth factor in human prostate cancer. Am J Pathol. 2001; 159: 2159-65.

5. Small EJ, Smith MR, Seaman JJ, Petrone S, Kowalski MO: Combined analysis of two multicenter, randomized, placebo-controlled studies of pamidronate disodium for the palliation of bone pain in men with metastatic prostate cancer. J Clin Oncol. 2003; 21: 4277-84.

6. Saad F, Gleason DM, Murray R, Tchekmedyian S, Venner P, Lacombe L, ET AL.: A randomized, placebo-controlled trial of zoledronic acid in patients with hormone-refractory metastatic prostate carcinoma. J Natl Cancer Inst. 2002; 94: 1458-68.

7. Shipman CM, Rogers MJ, Apperley JF, Russell RG, Croucher PI: Bisphosphonates induce apoptosis in human myeloma cell lines: a novel anti-tumour activity. Br J Haematol. 1997; 98: 665-72.

8. Fromigue O, Lagneaux L, Body JJ: Bisphosphonates induce breast cancer cell death in vitro. J Bone Miner Res. 2000; 15: 2211-21.

9. Lee MV, Fong EM, Singer FR, Guenette RS: Bisphosphonate treatment inhibits the growth of prostate cancer cells. Cancer Res. 2001; 61: 2602-8.

10. Oades GM, Senaratne SG, Clarke IA, Kirby RS, Colston KW: Nitrogen containing bisphosphonates induce apoptosis and inhibit the mevalonate pathway, impairing Ras membrane localization in prostate cancer cells. J Urol. 2003; 170: 246-52.

11. Chung TD, Yu JJ, Spiotto MT, Bartkowski M, Simons JW: Characterization of the role of IL-6 in the progression of prostate cancer. Prostate. 1999; 38: 199-207.

12. Kishimoto T, Akira S, Taga T: Interleukin-6 and its receptor: a paradigm for cytokines. Science. 1992; 258: 593-7.

13. Kishimoto T: The biology of interleukin-6. Blood. 1989; 74: 1-10.

14. Twillie DA, Eisenberger MA, Carducci MA, Hseih WS, Kim WY, Simons JW: Interleukin-6: a candidate mediator of human prostate cancer morbidity. Urology. 1995; 45: 542-9.

15. Shariat SF, Andrews B, Kattan MW, Kim J, Wheeler TM, Slawin KM: Plasma levels of interleukin-6 and its soluble receptor are associated with prostate cancer progression and metastasis. Urology. 2001; 58: 100815. 
16. Borsellino N, Belldegrun A, Bonavida B: Endogenous interleukin 6 is a resistance factor for cis-diamminedichloroplatinum and etoposide-mediated cytotoxicity of human prostate carcinoma cell lines. Cancer Res. 1995; 55: 4633-9.

17. Tenta R, Tiblalexi D, Sotiriou E, Lembessis P, Manoussakis M, Koutsilieris M: Bone microenvironment-related growth factors modulate differentially the anticancer actions of zoledronic acid and doxorubicin on PC-3 prostate cancer cells. Prostate. 2004; 59: 12031.

18. Lou W, Ni Z, Dyer K, Tweardy DJ, Gao AC: Interleukin-6 induces prostate cancer cell growth accompanied by activation of stat 3 signaling pathway. Prostate. 2000; 42: 239-42.

19. Borsellino N, Bonavida B, Ciliberto G, Toniatti C, Travali S, D’Alessandro N: Blocking signaling through the Gp130 receptor chain by interleukin-6 and oncostatin M inhibits PC-3 cell growth and sensitizes the tumor cells to etoposide and cisplatin-mediated cytotoxicity. Cancer. 1999; 85: 134-44.

20. Okamoto M, Lee C, Oyasu R: Interleukin-6 as a paracrine and autocrine growth factor in human prostatic carcinoma cells in vitro. Cancer Res. 1997; 57: 1416.

21. Mori S, Murakami-Mori K, Bonavida B: Oncostatin $\mathrm{M}(\mathrm{OM})$ promotes the growth of DU 145 human prostate cancer cells, but not PC-3 or LNCaP, through the signaling of the OM specific receptor. Anticancer Res. 1999; 19: 1011-5.

22. Klein B, Zhang XG, Jourdan M, Content J, Houssiau F, Aarden L, et al.: Paracrine rather than autocrine regulation of myeloma-cell growth and differentiation by interleukin-6. Blood. 1989; 73: 517-26.

23. Miki S, Iwano M, Miki Y, Yamamoto M, Tang B, Yokokawa K, et al.: Interleukin-6 (IL-6) functions as an in vitro autocrine growth factor in renal cell carcinomas. FEBS Lett. 1989; 250: 607-10.

24. Cavarretta IT, Neuwirt H, Untergasser G, Moser PL, Zaki MH, Steiner H, et al.: The antiapoptotic effect of
IL-6 autocrine loop in a cellular model of advanced prostate cancer is mediated by Mcl-1. Oncogene. 2007; 26: 2822-32.

25. Boissier S, Ferreras M, Peyruchaud O, Magnetto S, Ebetino FH, Colombel M, et al.: Bisphosphonates inhibit breast and prostate carcinoma cell invasion, an early event in the formation of bone metastases. Cancer Res. 2000; 60: 2949-54.

26. Neville-Webbe HL, Rostami-Hodjegan A, Evans CA, Coleman RE, Holen I: Sequence- and schedule-dependent enhancement of zoledronic acid induced apoptosis by doxorubicin in breast and prostate cancer cells. Int J Cancer. 2005; 113: 364-71.

27. Ullen A, Lennartsson L, Harmenberg U, Hjelm-Eriksson M, Kalkner KM, Lennernas B, et al.: Additive/synergistic antitumoral effects on prostate cancer cells in vitro following treatment with a combination of docetaxel and zoledronic acid. Acta Oncol. 2005; 44: 644-50.

28. Derenne S, Amiot M, Barillé S, Collette M, Robillard $\mathrm{N}$, Berthaud $\mathrm{P}$, et al.: Zoledronate is a potent inhibitor of myeloma cell growth and secretion of IL- 6 and MMP-1 by the tumoral environment. J Bone Miner Res. 1999; 14: 2048-56.

29. Corso A, Ferretti E, Lunghi M, Zappasodi P, Mangiacavalli S, De Amici M, et al.: Zoledronic acid downregulates adhesion molecules of bone marrow stromal cells in multiple myeloma: a possible mechanism for its antitumor effect. Cancer. 2005; 104: 118-25.

30. Dicuonzo G, Vincenzi B, Santini D, Avvisati G, Rocci L, Battistoni F, et al.: Fever after zoledronic acid administration is due to increase in TNF-alpha and IL-6. J Interferon Cytokine Res. 2003; 23: 649-54.

31. Eaton CL, Coleman RE: Pathophysiology of bone metastases from prostate cancer and the role of bisphosphonates in treatment. Cancer Treat Rev. 2003; 29: 189-98.

32. Smith PC, Hobisch A, Lin DL, Culig Z, Keller ET: Interleukin- 6 and prostate cancer progression. Cytokine Growth Factor Rev. 2001; 12: 33-40.

\footnotetext{
Correspondence address:

Dr. Cag Cal

Department of Urology

Ege University Tip Fakultesi

Izmir, Turkey

Fax: + 90232 421-5533

E-mail: cag.cal@ege.edu.tr
} 


\section{EDITORIAL COMMENT}

Interleukin-6 (IL-6) is an important regulator of cellular events in human prostate cancer. It has multifunctional effects on proliferation, apoptosis, and angiogenesis and is a target for novel therapies. Most studies were performed with the anti-IL-6 antibody CNTO 328 in vitro and in vivo (1-3). They have demonstrated differences in responsiveness to the antibody between these two different cell lines. The authors of the present paper show that zoledronic acid, that is used for late stage prostate cancer treatment, has a negative effect on IL-6 expression. This is a novel important aspect of action of that drug in human prostate cancer therapy. Since IL-6 is considered a survival factor in some but not all human prostate cancers, this therapy may increase rate of cell death. However, growth-inhibitory effects of IL-6 in selected cell lines were also observed. For that reason, it is important to determine who are the patients who will benefit from anti-IL-6 therapy in the future. In summary, the manuscript by Asbagh et al. is translationally relevant and may stimulate research on IL-6 regulatory effects in prostate cancer in the future.

\section{REFERENCES}

1. Smith PC, Keller ET: Anti-interleukin-6 monoclonal antibody induces regression of human prostate cancer xenografts in nude mice. Prostate. 2001; 48: 47-53.

2. Zaki MH, Nemeth JA, Trikha M: CNTO 328, a monoclonal antibody to IL-6, inhibits human tumor-induced cachexia in nude mice. Int J Cancer. 2004; 111: 5925.

3. Steiner H, Cavarretta IT, Moser PL, Berger AP, Bektic $\mathrm{J}$, Dietrich H, et al.: Regulation of growth of prostate cancer cells selected in the presence of interleukin-6 by the anti-interleukin- 6 antibody CNTO 328. Prostate. 2006; 66: 1744-52.
Dr. Zoran Culig Department of Urology Innsbruck Medical University Innsbruck, Austria E-mail: zoran.culig@uibk.ac.at 